See Article page 2025 .

\section{Commentary: Accurate prediction of aortic dissection and rupture: The elusive holy grail}

\author{
Christopher Lau, MD, and Leonard N. Girardi, MD
}

The quest to discover the optimal criteria for prophylactic aortic aneurysm repair to minimize the risk of aortic dissection has been a long and winding road. The journey began with aortic diameter, ${ }^{1}$ which has served admirably, yet imperfectly, for quite some time. The use of diameter is based on Laplace's law, which uses pressure and radius to derive a measure of tension $(\mathrm{T}=\mathrm{p} \times \mathrm{r})$. However, it does not take into account other physical and mechanical properties of the wall itself, which play a part in the risk of rupture or dissection. Notably, Laplace's law pertains to a perfect cylinder but the aorta is an expansible structure, which can absorb some kinetic energy-associated systolic ejection.

Czerny and colleagues ${ }^{2}$ discuss the need to use additional parameters to predict the occurrence of acute type A aortic dissection (ATAAD). Their reasoning for the need for this discussion is the commonly stated, but somewhat misperceived, notion that most ATAAD now occur at $<5.5 \mathrm{~cm}$ so we need to consider operating at smaller sizes. However, the main reason that most ATAAD now occur at smaller sizes is that most aneurysms are repaired prophylactically before they reach larger sizes. Only a natural history study could tell us whether aneurysms are more likely to dissect at smaller diameters and the closest available evidence refutes this. $^{3}$

Although the authors are correct that a more accurate prediction model would benefit patients at risk of ATAAD at smaller diameters, their proposed solution raises concerns. The authors provide a brief review of several parameters such as indexing to body surface area, aortic length, and aortic

From the Department of Cardiothoracic Surgery, Weill Cornell Medicine, New York, NY.

Disclosures: The authors reported no conflicts of interest.

The Journal policy requires editors and reviewers to disclose conflicts of interest and to decline handling or reviewing manuscripts for which they may have a conflict of interest. The editors and reviewers of this article have no conflicts of interest.

Received for publication Feb 21, 2021; revisions received Feb 21, 2021; accepted for publication Feb 22, 2021; available ahead of print Feb 27, 2021.

Address for reprints: Leonard N. Girardi, MD, Department of Cardiothoracic Surgery, Weill Cornell Medicine, 525 E 68th St, M-404, New York, NY 10065 (E-mail: lngirard@med.cornell.edu).

J Thorac Cardiovasc Surg 2022;163:2034-5

0022-5223/\$36.00

Copyright $(2) 2021$ by The American Association for Thoracic Surgery

https://doi.org/10.1016/j.jtcvs.2021.02.079
Check for updates

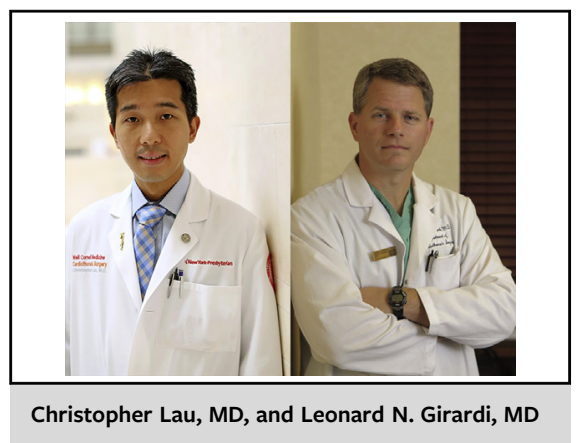

CENTRAL MESSAGE

Risk of aortic dissection depends

on a multitude of factors. Multi-

variable predictive models may

be ideal, but their use must not

be too cumbersome.

height index ${ }^{4}$ and found that all of these are potentially flawed. Although their review was not completely inclusive, even in our recently published detailed review of currently available aortic parameters used to predict adverse aortic events, we were not able to identify any single well-proven parameter to use. ${ }^{5}$ The authors then mention the significance of aortic morphology, genetic conditions, and complex imaging findings using 4-dimensional flow magnetic resonance imaging, computational fluid dynamics, and finite element analysis. They propose that a multifactorial predictive nomogram based on aortic length is the solution. However, it would be impossible for a nomogram to incorporate the amount of data that the authors propose to be included. A complex multivariable risk calculator would be more appropriate. Additionally, for any tool to work in real-world practice, it cannot be overly cumbersome. Many of the elements of the authors' proposed model would require specialized imaging or measurements that are not reported in normal practice. It would require the surgeon to make specific measurements and reanalyze every imaging study. This would be an arduous task at best and would be impossible in a busy aortic practice. Although we agree that the field can do better than simple aortic diameter, the authors' vision of the solution may be more of a wish than an attainable reality at this time.

\section{References}

1. Coady MA, Rizzo JA, Hammond GL, Mandapati D, Darr U, Kopf GS, et al. What is the appropriate size criterion for resection of thoracic aortic aneurysms? J Thorac Cardiovasc Surg. 1997;113:476-91. 
2. Czerny M, Rylski B, Della Corte A, Krüger T. Decision-making to perform elective surgery for patients with proximal thoracic aortic pathology: a European perspective. J Thorac Cardiovasc Surg. 2022;163:2025-30.

3. Davies RR, Goldstein LJ, Coady MA, Tittle SL, Rizzo JA, Kopf GS, et al. Yearly rupture or dissection rates for thoracic aortic aneurysms: simple prediction based on size. Ann Thorac Surg. 2002;73:17-27.
4. Svensson LG, Kim K-H, Lytle BW, Cosgrove DM. Relationship of aortic cross-sectional area to height ratio and the risk of aortic dissection in patients with bicuspid aortic valves. J Thorac Cardiovasc Surg. 2003;126: 892-3.

5. Girardi LN, Lau C, Gambardella I. Aortic dimensions as predictors of adverse events. J Thorac Cardiovasc Surg. 2021;161:1193-7. 